\title{
An Experimental Analysis of Pervious Concrete Side Drains to Avoid Urban Water Logging
}

\author{
Prof. Sameer Shah \\ Civil Engineering Department \\ Faculty at PVPIT, Bavdhan \\ Pune, India. \\ Rushikesh Satishrao Deshmukh \\ Civil Engineering Department \\ PVPIT, Bavdhan \\ Pune, India.
}

\author{
Sourabh Shivaji Bhandari \\ Civil Engineering Department \\ PVPIT, Bavdhan \\ Pune, India.
}

\author{
Shreyas Rajendra Nigade \\ Civil Engineering Department \\ PVPIT, Bavdhan \\ Pune, India.
}

\begin{abstract}
Pervious concrete (no-fines concrete) is a concrete containing little or no fine aggregate; it consists of coarse aggregate and cement paste. It seems pervious concrete would be a natural choice for use in structural applications in this age of 'green building'. It consumes less raw material than normal concrete (no sand), it provides superior insulation values when used in walls, and through the direct drainage of rainwater, it helps recharge groundwater in pavement applications. The first pervious concrete has been used in Europe and the United Kingdom since1930s for the building of single story and multistory houses, but had found little acceptance in rest of the world. In recent years, however, due to increased awareness of the need for conservation of nonrenewable mineral resources, increased consideration is being given to the use of yet widely used in Sri Lanka, pervious concrete is generally used for lightduty pavement applications, such as residential streets, parking lots, drive ways, side-walks, channel lining, retaining walls and sound walls.

.Main objective of pervious concrete are :-

1. To help restore ground water supply.

2. Reduce pollution of coastal water;

3. To pave parking.•Recharge ground water table.

4. Reduces runoff water

5. Reduces risk of flooding and topsoil wash away.
\end{abstract}

Key Words: No fine aggregates, permeable, runoff, pave parking, ground water, interconnectivity etc

\section{INTRODUCTION}

Pervious concrete is also a unique and effective means to address important environmental issues and sustainable growth. When it rains, pervious concrete automatically acts as a drainage system, thereby putting water back where it belongs. Pervious concrete is rough textured, and has a honeycombed surface, with moderate amount of surface raveling which occurs on heavily travelled roadways (Concrete network, 2009). Carefully controlled amount of water and cementitious materials are used to create a paste (Dan, 2003). The paste then forms a thick coating around aggregate particles, to prevent the flowing off of the paste during mixing and placing. Using enough paste to coat the particles maintain a system of interconnected voids which allow water and air to pass through. The lack of sand in pervious concrete results in a very harsh mix that negatively affects mixing, delivery and placement. Also, due to the high void content, pervious concrete is light in weight (about 1600 to $1900 \mathrm{~kg} / \mathrm{m} 3$ ). Pervious concrete void structure provides pollutant captures which also add significant structural strength as well. It also results in a very high permeable concrete that drains quickly.

Over the last few years, pervious concrete has become a very relevant topic in the construction industry. More and more specifications call for pervious concrete in different applications. Some of these applications include parking lots, sidewalks and even pavers where in the past these were solely the domain of conventional concrete or black top. The popularity of pervious concrete continues to rise with the increased awareness of environmental protection and preservation. Pervious concrete is recognized by United States Green Building Council (USGBC), which sets the green building rating system known as the LEED program (The Leadership in Energy and Environmental Design). The LEED program is the nationally accepted benchmark for the design, construction, and operation of high performance "green" buildings.

Pervious concrete system has advantages over impervious concrete in that it is effective in managing run-off from paved surfaces, prevent contamination in run-off water, and recharge aquifer, repelling salt water intrusion, control pollution in water seepage to ground water recharge thus, preventing subterranean storm water sewer drains, absorbs less heat than regular concrete and asphalt, reduces the need for air conditioning. Pervious concrete allows for increased site optimization because in most cases, its use should totally limit the need for detention and retention ponds, swales and other more traditional storm water management devices that are otherwise required for compliances with the Federal storm water regulations on commercial sites of one acre or more.

By using pervious concrete, the ambient air temperature will be reduced, requiring less power to cool the building. In addition, costly storm water structures such as piping, inlets and ponds will be eliminated. 


\section{PROBLEM STATMENT}

As observed in recent years the unpredictable and adverse rainfall in many areas and states of the nation the problem of effective drains have risen to the high extent. Recently in Mumbai, Maharashtra the amount of rainfall was extreme leaving us with unplanned drainage systems and flooded streets. This phenomenon caused stagnation of economical and daily routine of entire Mumbai city for a couple of weeks. It also showed its bad effects on civilian assets (flooding in homes, cars and properties were washed off in floods) and significant human lives endangering the nearby livelihood. Small scale business owners and labors suffered the adverse effects of this rainfall. Sewers and drains are not efficient to manage the excess water from the storm and floods. Lack of maintenance and irregular cleaning schedules cause the inefficiency of these drains. It is somewhat of a balancing act to develop a pervious concrete mix that places easily, performs well, and has good durability. Generally problems with pervious concrete mixtures are related to water content, mixture proportions. Some material-related issues can be remediated by changing construction practices, but this article only covers suggested changes from the concrete producer's perspective.

- To develop and maintain standards for the design, construction, maintenance, and rehabilitation of pervious concrete.

- This recent interest in porous surfaces as a substitution for impervious surfaces can be attributed to desirable benefits such as storm water retention, which includes storm water treatment.

- Increased regulations for storm water management, there has been a need for pavements that minimize surface runoff.

\section{MATERIALS USED}

\section{Constituents of concrete}

If a concrete is to be suitable for a particular purpose, it is necessary to select the constituent materials and combine them in such a manner as to develop the special qualities required as economical as possible. The selection of materials and choice of method of construction is not easy, since many variables affect the quality of the concrete produced, and both quality and economy must be considered. The characteristics of concrete should be evaluated in relation to the required quality for any given construction purpose. The closest practicable approach to perfection in every property of the concrete would result in poor economy under many conditions, and the most desirable structure is that in which the concrete has been designed with the correct emphasis on each of the various properties of the concrete, and not solely with a view to obtaining of maximum possible strength.

\section{Cement}

Cement is a key to infrastructure industry and is used for various purposes and also made in many compositions for a wide variety of uses. Cements may be named after the principal constituents, after the intended purpose, after the object to which they are applied or after their characteristic property.

Cement used in construction are sometimes named after their commonly reported place of origin, such as Roman cement, or for their resemblance to other materials, such as Portland cement, which produces a concrete resembling the Portland stone used for building in Britain. The term cement is derived from the Latin word Caementum, which is meant stone chippings such as used in Roman mortar not-the binding material itself.

suppliers.

\section{Aggregates}

Aggregates were first considered to simply be filler for concrete to reduce the amount of cement required. However, it is now known that the type of aggregate used for concrete can have considerable effects on the plastic and hardened state properties of concrete. They can form $80 \%$ of the concrete mix so their properties are crucial to the properties of concrete.

Aggregates can be broadly classified into four different categories: these are heavyweight, normal weight, lightweight and ultra-lightweight aggregates. However in most concrete practices only normal weight and light weight aggregates are used. The other types of aggregates are for specialist uses, such as nuclear radiation shielding provided by heavy weight concrete and thermal insulation using lightweight concrete.

\section{Classification of aggregates}

The alternative used in the manufacture of good quality concrete, is to obtain the aggregate in at least two size groups, i.e.:

1. fine aggregate often called sand not larger than $5 \mathrm{~mm}$ in size.

2. course aggregate, which comprises material at least $5 \mathrm{~mm}$ in size.

On the other hand, there are some properties possessed by the aggregate but absent in the parent rock: particle shape and size, surface texture, and absorption. All these properties have a considerable influence on the quality of the concrete, either in fresh or in the hardened state. It has been found that aggregate may appear to be unsatisfactory on some count but no trouble need be experienced when it is used in concrete

\section{Aggregate properties}

By selecting different sizes and types of aggregates and different ratios of aggregate to cement ratios, a wide range of concrete can be produced economically to suit different requirements. Important properties of an aggregate which affect the performance of a concrete are discussed as follows:

\section{Sampling}

Samples shall be representative and certain precautions in sampling have to be made. No detailed procedures can be laid down as the conditions and situations involved in taking samples in the field can vary widely from case to case. Nevertheless, a practitioner can obtain reliable results bearing in mind that the sample taken is to be representative of the bulk of the material. The main sample shall be made up of portions drawn from different parts of the whole. The 
minimum number of these portions. In the case of stockpiles, the sample obtained is variable or segregated, a large number of increments should be taken and a larger sample should be dispatched for testing.

\section{Particle shape and texture}

Roundness measures the relative sharpness or angularity of the edges and corners of a particle. Roundness is controlled largely by the strength and abrasion resistance of the parent rock and by the amount of wear to which the particle has been subjected. In the case of crushed aggregate, the particle shape depends not only on the nature of the parent rock but also on the type of crusher and its reduction ratio, i.e. the ratio of the size of material fed into the crusher to the size of the finished product. Particles with a high ratio of surface area to volume are also of particular interest for a given workability of the control mix. Elongated and flaky particles are departed from equi-dimensional shape of particles and have a larger surface area and pack in an isotropic manner. Flaky particles affect the durability of concrete, as the particles tend to be oriented in one plane, with bleeding water and air voids forming underneath. The flakiness and elongation tests are useful for general assessment of aggregate but they do not adequately describe the particle shape. The presence of elongated particles in excess of 10 to $15 \%$ of the mass of coarse aggregate is generally undesirable, but no recognized limits are laid down .Surface texture of the aggregate affects its bond to the cement paste and also influences the water demand of the mix, especially in the case of fine aggregate. The shape and surface texture of aggregate influence considerably the strength of concrete. The effects of shape and texture are particularly significant in the case of high strength concrete.

The full role of shape and texture of aggregate in the development of concrete strength is not known, but possibly a rougher texture results in a larger adhesive force between the particles and the cement matrix.Likewise, the larger surface area of angular aggregate means that a larger adhesive force can be developed.

The shape and texture of fine aggregate have a significant effect on the water requirement of the mix made with the given aggregate. If these properties of fine aggregate are expressed indirectly by it's packing, i.e. by the percentage voids in a loose condition, then the influence on the water requirement is quite definite. The influence of the voids in coarse aggregate is less definite. Flakiness and shape of coarse aggregates have an appreciable effect on the workability of concrete.

\section{Bond of aggregate}

Bond between aggregate and cement paste is an important factor in the strength of concrete, but the nature of bond is not fully understood. Bond is to the interlocking of the aggregate and the hydrated cement paste due to the roughness of the surface of the former. A rougher surface, such as that of crushed particles, results in a better bond due to mechanical interlocking; better bond is not usually obtained with softer, porous, and minor logically heterogeneous particles. Bond is affected by the physical and chemical properties of aggregate. For good development of bond, it is necessary that the aggregate surface be clean and free from adhering clay particles .The determination of the quality of bond of aggregate is difficult and no accepted tests exist. Generally, when bond is good, a crushed specimen of normal strength concrete should contain some aggregate particles broken right through, in addition to the more numerous ones pulled out from their sockets. An excess of fractured particles, might suggest that the aggregate is too weak.

\section{Strength of aggregate}

The compressive strength of concrete cannot significantly exceed that of the major part of the aggregate contained. If the aggregate under test leads to a lower compressive strength of concrete, and in particular if numerous individual aggregate particles appear fractured after the concrete specimen has been crushed, then the strength of the aggregate is lower than the nominal compressive strength of the concrete mix. Such aggregate can be used only in a concrete of lower strength.

The influence of aggregate on the strength of concrete is not only due to the mechanical strength of the aggregate but also, to a considerable degree, to its absorption and bond characteristics. In general, the strength of aggregate depends on its composition, texture and structure. Thus a low strength may be due to the weakness of constituent grains or the grains may be strong but not well knit or cemented together.

A test to measure the compressive strength of prepared rock cylinders used to be prescribed. However, the results of such a test are affected by the presence of planes of weakness in the rock that may not be significant once the rock has been comminuted to the size used in concrete. In essence the crushing strength test measures the quality of the parent rock rather than the quality of the aggregate as used in concrete. For this reason the test is rarely used. Crushing value test BS 812: part 105:1990, measures the resistance to pulverization. The crushing value is a useful guide when dealing with aggregates of unknown performance, when lower strength may be suspected. There is no obvious physical relation between this crushing value and the compressive strength, but the results of the two tests are usually in agreement.

\section{Deleterious substances of aggregate}

For satisfactory performance, concrete aggregates should be free of deleterious materials. There are three categories of deleterious substances that may be found in aggregates: impurities, coatings and weak or unsound particles.

\section{Grading of fine and coarse aggregate}

The actual grading requirements depend on the shape and surface characteristics of the particles. For instance, sharp angular particles with rough surfaces should have a slightly finer grading in order to reduce the possibility of interlocking and to compensate for the high friction between the particles

\section{Maximum aggregate size}

Extending the grading of aggregate to a larger maximum size lowers the water requirement of the mix, so that, for a specified workability and cement content, the water /cement ratio can be lowered with a consequent increase in strength Experimental results indicated that above the $38 \mathrm{~mm}$ 
maximum size the gain in strength due to the reduced water requirement is offset by the detrimental effects of lower bond area (so that volume changes in the paste cause larger stresses at interfaces) and of discontinuities introduced by the very large particles. In structural concrete of usual proportions, there is no advantage in using aggregate with a maximum size greater than about 25 or $40 \mathrm{~mm}$ when compressive strength is a criterion.

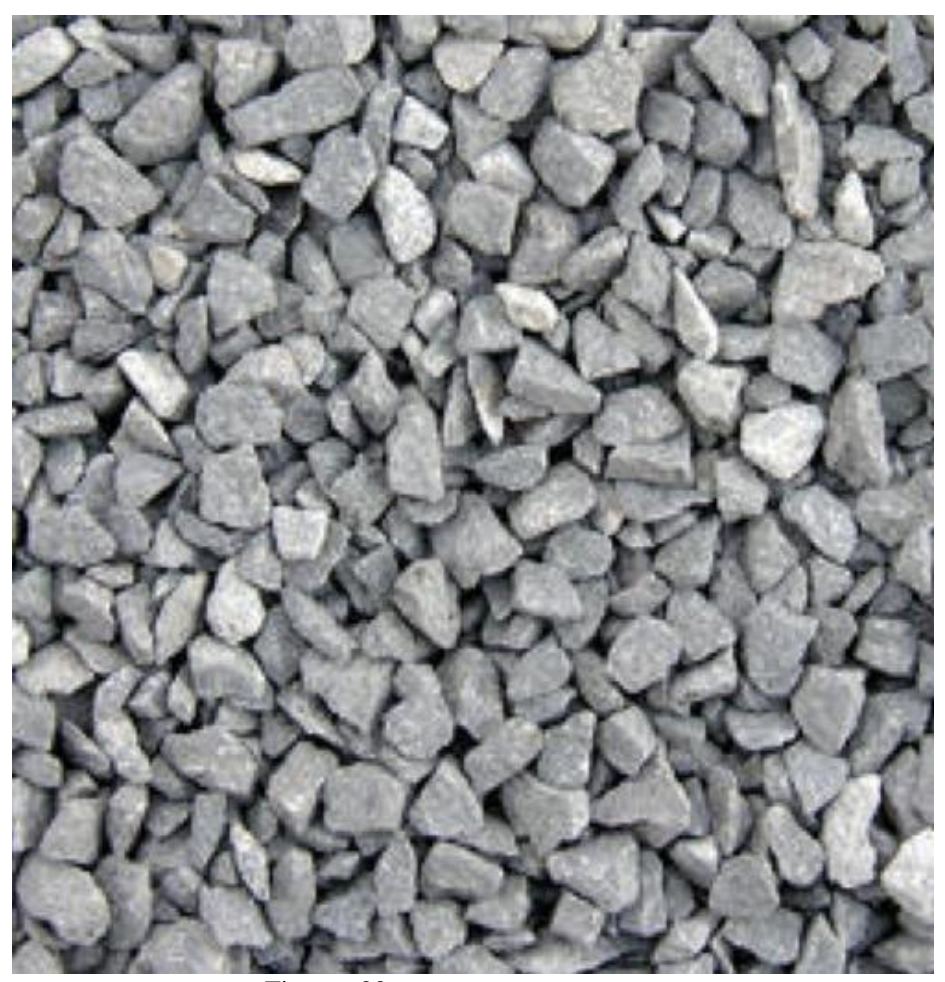

Figure : $20 \mathrm{~mm}$ coarse aggregate

\section{Water}

Water is a key ingredient in the manufacture of concrete. Water used in concrete mixes has two functions: the first is to react chemically with the cement, which will finally set and harden, and the second function is to lubricate all other materials and make the concrete workable. Although it is an important ingredient of concrete, it has little to do with the quality of concrete. One of the most common causes of poorquality concrete is the use of too much mixing water. Fundamentally "the strength of concrete is governed by the nature of the weight of water to the weight of cement in a mix, provided that it is plastic and workable, fully compacted, and adequately cured".

\section{PREPARATION OF CUBE SPECIMN}

The proportion and material for making these test specimens are from the same concrete used in the field.

\section{Mixing}

Mix the concrete either by hand or in a laboratory batch mixer
1. Mix the cement and fine aggregate on a water tight none-absorbent platform until the mixture is thoroughly blended and is of uniform colour

2. Add the coarse aggregate and mix with cement and fine aggregate until the coarse aggregate is uniformly distributed throughout the batch

3. Add water and mix it until the concrete appears to be homogeneous and of the desired consistency

Figure: Mixing of pervious concrete

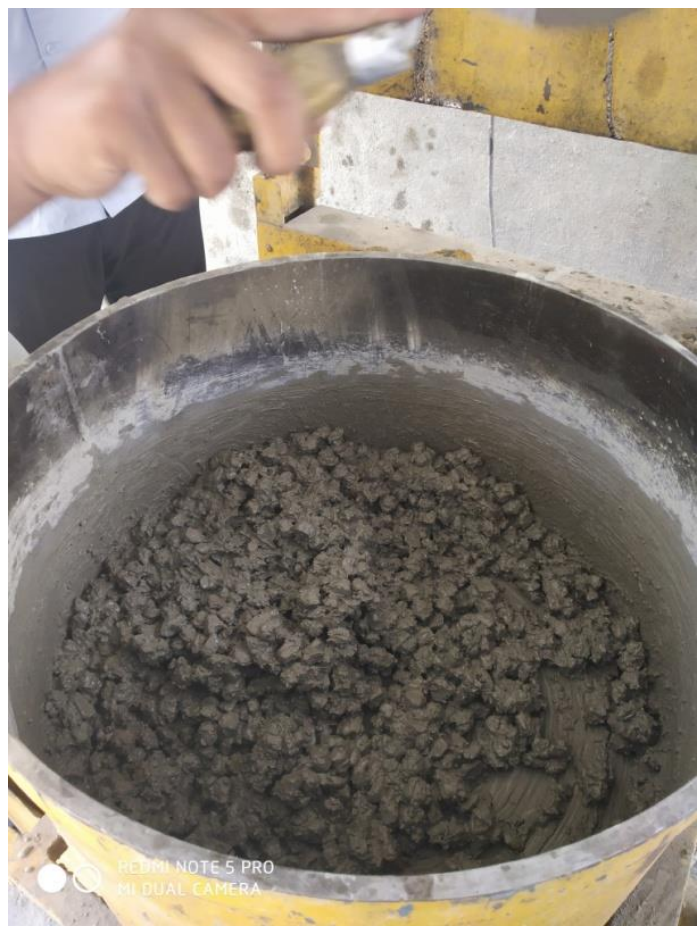

Figure : Prepared mix

\subsubsection{Sampling}

1. Clean the mounds and apply grease.

2. Fill the concrete in the moulds in 3 equal layers

3. Compact each layer with not less than 35 strokes per layer using a tamping rod (steel bar $16 \mathrm{~mm}$ diameter and $60 \mathrm{~cm}$ long, bullet pointed at lower end)

4. Level the top surface and smoothen it with a trowel

\subsubsection{Curing}

The test specimens are stored in moist air for 24hours and after this period the specimens are marked and removed from the moulds and kept submerged in clear fresh water until taken out prior to test.

\subsubsection{Procedure:}

1. Remove the specimen from water after specified curing time and wipe out excess water from the surface.

2. Take the dimension of the specimen to the nearest $0.2 \mathrm{~m}$

3. Clean the bearing surface of the testing machine 
4. Place the specimen in the machine in such a manner that the load shall be applied to the opposite sides of the cube cast.

5. Align the specimen centrally on the base plate of the machine.

6. Rotate the movable portion gently by hand so that it touches the top surface of the specimen.

7. Apply the load gradually without shock and continuously at the rate of $140 \mathrm{~kg} / \mathrm{cm} 2 /$ minute till the specimen fails

8. Record the maximum load and note any unusual features in the type of failure.

\section{COMPRESSIVE STRENGTH OF PERVIOUS CONCRETE:}

In the laboratory, pervious concrete mixtures have been found to develop compressive strengths in the range of 3.5 $\mathrm{MPa}$ to $28 \mathrm{MPa}$, which is suitable for a wide range of applications. Typical values are about $17 \mathrm{MPa}$. As with any concrete, the properties and combinations of specific materials, as well as placement techniques and environmental conditions, will dictate the actual in-place strength. However, currently there is no ASTM test standard for compressive strength of pervious concrete.

Testing variability measured with various draft test methods has been found to be high and therefore compressive strength is not recommended as an acceptance criterion. Rather, it is recommended that a target void content (between $15 \%$ to $25 \%$ ) as measured by ASTM C 1688: Standard Test Method for Density and Void Content of Freshly Mixed Pervious

\begin{tabular}{|c|c|cc|}
\hline SR NO & $\begin{array}{c}\text { AGE OF } \\
\text { CONCRETE }\end{array}$ & \multicolumn{3}{|c|}{$\begin{array}{c}\text { COMPRESSIVE STRENGTH } \\
\text { (MPA) }\end{array}$} \\
\hline 1 & 7 days & ${ }^{19}$ & 12.26 \\
\hline 2 & 14 days & ${ }^{20}$ & 15.02 \\
\hline 3 & 28 days & ${ }^{21}$ & 15.76 \\
\hline
\end{tabular}

Concrete be specified for quality assurance and acceptance.

\section{DENSITY AND POROSITY:}

The density of pervious concrete depends on the properties and proportions of the materials used, and on the compaction procedures used in placement. In-place densities on the order of $1600 \mathrm{~kg} / \mathrm{m}^{3}$ to $2100 \mathrm{~kg} / \mathrm{m}^{3}$ are common, which is in the upper range of lightweight concretes. A pavement $125 \mathrm{~mm}$ thick with $20 \%$ voids will be able to store $25 \mathrm{~mm}$ of a sustained rainstorm in its voids, which covers the vast majority of rainfall events in the U.S.

\section{PERMEABILITY OF PERVIOUS CONCRETE:}

The permeability of pervious concrete was determined using a falling head permeability set up. Water was allowed to flow through the sample, through a connected standpipe which provides the water head. Before starting the flow measurement, the samples were wrapped with polythene inside the cylinder. Then the test started by allowing water to flow through the sample until the water in the standpipe reached a given lower level. A constant time of 5seconds was taken for the water to fall from one head to another in the standpipe. The standpipe was refilled and the test was repeated when water reached a lower. The permeability of the pervious concrete sample was evaluated from the expression given below:

\section{EXPERIMENTAL VALUES}

\section{RESULTS OF EXPERIMENTS CONDUCTED ON} MATERIALS

1. CEMENT ( OPC 53 GRADE CEMENT)

- $\quad$ Specific gravity :3.02

- $\quad$ Fineness of cement :3.15

- Consistency :35\%

- Initial setting time : $120 \mathrm{~min}$.

2. COARSE AGgREgATE

- Specific gravity :3.00

- Bulk density :1.50

\begin{tabular}{|ll|ll|}
\hline 1 & Age & 2 & Strength per cent \\
& & & \\
\hline 4 & 1 day & 5 & $16 \%$ \\
& & 6 & \\
\hline 7 & 3 days & 8 & $40 \%$ \\
& & 9 & \\
\hline 10 & 7 days & 11 & $65 \%$ \\
& & 12 & \\
\hline 13 & 14 days & 14 & $90 \%$ \\
& & 15 & \\
\hline 16 & 28 days & 17 & $99 \%$ \\
& & 18 & \\
\hline
\end{tabular}

\section{COMPRESSIVE STRENGTH OF CUBES}

Compressive strength at 7 days and 14days of $20 \mathrm{~mm}$ aggregates size cubes

\section{DESIGN PARAMETERES}

- $\quad$ Load category $=$ Class $B$

IRC:6-2016

- $\quad$ Axle load $=68 \mathrm{kn} / \mathrm{m}^{2}$

......clause 201of IRC:6-2016

- $\quad$ Ground contact area $=0.5 \mathrm{~m}^{2}$ ......table no. 4 of IRC:6-2016

- $\quad$ Impact factor $=4.5 /(6.5+\mathrm{L})=4.5 /(6.5+5)=0.489$ ...... From clause 208.2 of IRC:6-2016 


\begin{tabular}{|c|c|c|c|c|}
\hline \multicolumn{5}{|c|}{$\begin{array}{l}\text { VII. COST ANALYSIS } \\
\text { Cost Comparison of Normal Concrete of M20 grade and } \\
\text { Pervious Concrete }\end{array}$} \\
\hline Material & $\begin{array}{c}\text { Normal } \\
\text { Concrete of } \\
\text { M20 Grade }\end{array}$ & $\begin{array}{c}\text { Rupees } \\
/ \mathrm{m}^{3}\end{array}$ & $\begin{array}{l}\text { Pervious } \\
\text { Concrete }\end{array}$ & $\begin{array}{c}\text { Rupees } \\
/ \mathrm{m}^{3}\end{array}$ \\
\hline $\begin{array}{c}\text { Cement } \\
(300 \mathrm{Rs} / 50 \\
\mathrm{kg})\end{array}$ & $59.25 \mathrm{~kg}$ & 356 & $46.5 \mathrm{~kg}$ & 279 \\
\hline $\begin{array}{l}\text { Fine } \\
\text { aggregate } \\
\text { (600 Rs/ton) }\end{array}$ & $88.88 \mathrm{~kg}$ & 53 & - & - \\
\hline $\begin{array}{l}\text { Coarse } \\
\text { Aggregate } \\
\text { (1000 Rs / } \\
\text { ton) }\end{array}$ & $177.8 \mathrm{~kg}$ & 178 & $279 \mathrm{~kg}$ & 279 \\
\hline Total & & $587 \mathrm{Rs} /$ & & $\begin{array}{c}558 \mathrm{Rs} / \\
\mathrm{m}^{3}\end{array}$ \\
\hline
\end{tabular}

\section{VIII.SCOPE OF THE WORK}

1. Pervious concrete can be used in building for rainwater harvesting as well as for cooling purpose by providing permeable wall.

2. In the presence of clayey soil, water can be percolated through providing borehole at every 1$2 \mathrm{~km}$ with the help of drainage system.

3. Flaky aggregate can be use to provide easy passes of water without any extra drainage system provided. (Flaky aggregate have more strength).

4. Water can be filtered and stored as fresh water below the ground.

5. We can also give direction to water specifically according to need. By providing certain angle to the flaky aggregate water which gets drained will make its way to the slope going down towards the sewer line or any other drainage arrangement.

\section{MAINTAINANCE}

Prevent the surface from becoming clogged which reduce permeability. most site function well without regular maintenance if protected from sand. Vacuuming or power blowing may be necessary if the site become clogged.

Pressure washing has shown to improve permeability of clogged pavement to $80 \%$ to $90 \%$ of the original permeability.

The chance of clogging is highest during and just after construction and the site must be protected by an erosion control until vegetation has been established on the adjacent ground.

However pervious concrete work good in little or no maintenance but the main reason being debris and residue lodging on top of void structure maintenance is required.

Maintenance requirement cannot be determined because it changes with conditions and place to place and also on traffic condition.

\section{LITERATURE REVIEW}

In 2008, Kevern J. T., Schaefer V.R. et. al.

Studied the engineering properties of the aggregate of selected concrete mixtures. Concrete mixtures consist of single-sized river gravel aggregate $4.75 \mathrm{~mm}$ and constant binder contents, together with high range water reducer. River sand was used as a replacement for up to $7 \%$ coarse aggregate. Two different types of polypropylene fibres, a shorter fibrillated variable-length and a longer fibrillated single-legth were incorporated at several addition rates from 0 to $0.1 \%$ by volume of concrete. The results indicate that the use of sand and fibres provided beneficial effects on pervious concrete properties including increased strength, maintained or improved permeability and enhanced freeze-thaw resistance. Use of the short fibres improved the strength, permeability and freeze-thaw durability of the mixtures which did not contain additional sand. The long fibres improved the strength and freeze thaw durability of the mixtures which did not contain additional sand but did not improve permeability.

\section{In 2010, Omkar Deo, Narayanan Neithalath}

Studied that the properties of pervious concrete are strongly dependent on its pore structure features, porosity being an important one among them. Several pervious concrete mixtures

with different pore structure features are proportioned and subjected to static compression tests. The compressive stressstrain response of pervious concretes, a model to predict the stress-strain response and its relationship to several of the pore structure features are outlined. A statistical model was used to relate the compressive strength to the relevant pore structure features. It was observed that a proper understanding of the influence of pore structure features on compressive response can lead to optimized material design for the desired properties.

\section{In 1988, Meininger}

Studied the effect of different aggregate sizes $(10 \mathrm{~mm}$ and $19 \mathrm{~mm}$ ) on hardened properties of non-fine concretes and the results showed that compressive strength reduces with increase in aggregates size, which corresponded with the results found from Yang \& Jing (2003). It claimed the decrease of aggregate size led to higher pervious concrete strength, resulting from the increase of the interface strength between the aggregate and cement paste.

\section{In 2003, Jing Yang and Guoliang Jiang}

Studied that by using the common material and method, the strength of the pervious concrete is low. But using smaller aggregate, silica fume and super plasticizer in the previous concrete strength can be increased greatly. Also by increasing the cement paste binder area and enhancing the strength of cement binder pervious concrete strength can also be increased. The pervious pavement materials that composed of a surface layer and a base layer were made. The compressive strength of the pervious concrete can reach $50 \mathrm{MPa}$ and the flexural strength $6 \mathrm{MPa}$.

In 2004, D. Tennis Paul et. al.

Studied the replicated simples of pervious concrete formed from two rock sources for coarse aggregates and different size fractions to determine hydrologic relationships. Linear relationships were found between density and porosity, 
density and permeability, porosity and permeability, porosity and specific yield. The results suggest that properties such as permeability, porosity and specific yield are not significantly affected by different aggregate types.

\section{In 2006 Luck J.D., Workman S.R.}

They conducted laboratory study to evaluate the properties of high performance porous concrete. They used optimum mixture proportions in the preparation of high performance porous concretes containing three sizes of coarse aggregates with appropriate amount of high water-reducing and thickening agents. Its strength development rate was also examined at curing age $1,3,7,14$ and 28 days at $20 \mathrm{o} \mathrm{C}$ and $60 \%$ relative humidity. Consequently high performance porous concrete exhibited good workability and cohesiveness with no segregation or bleeding and developed high strength compared to conventional porous concrete.

\section{ACKNOWLEDGEMENT}

We have taken efforts in this project. However, it would not have been possible without the kind support and help of many individuals and organizations. I would like to extend my sincere thanks to all of them.

We are highly indebted to Prof. Shelake Sir for their guidance and constant supervision as well as for providing necessary information regarding the project \& also for their support in completing the project.

We would like to express my gratitude towards my parents \& member of our Group for their kind co-operation and encouragement which help me in completion of this project.
We would like to express my special gratitude and thanks to industry persons for giving me such attention and time.

Our thanks and appreciations also go to my colleague in developing the project and people who have willingly helped us out.

\section{REFERENCES}

[1] Experimental study of pervious concrete pavement vikram mahla R.P, International journal for Research In applied science and Technology vol3 Issue vii, july 2015 ISSN:2321-9653

[2] Urban storm water management through pervious concrete pavement by A.L.Guruji and B.A.Rana New era for Rural Road Pavement IJETT, vol 4 pp,3495, 8 august 2013

[3] Integrating Earned Value Management With Risk Management To Control The Time cost of the project by Ashkan Khoda Bandehlou, Mina lotfi Published 1october 2016

[4] Kevern, J. T., Schaefer, V. R., Wang, K., and Suleiman, M. T. "Pervious Concrete Mixture Proportions for Improved Freeze-Thaw Durability," Journal of ASTM International, Vol. 5, No. 2, 2008, pp. 1-12, https://doi.org/10.1520/JAI101320. ISSN 1546-962X

[5] Materials CharacterizationVolume 61, Issue 8, Characterizing pore volume, sizes, and connectivity in pervious concretes for permeability prediction August 2010, Pages 802-813

[6] Cement and Concrete Research , Experimental study on properties of pervious concrete pavement materials Volume 33, Issue 3, March 2003, Pages 381-386

[7] Published by the American Society of Agricultural and Biological Engineers, St. Joseph, Michigan www.asabe.org hydrological properties of pervious concrete Paper number 067063, 2006 ASAE Annual Meeting . (doi: 10.13031/2013.21029) @2006

[8] Atchison, D., Potter, K. W., \& Severson, L. (2006). Design Guidelines for Stormwater Bioretention Facilities. University of Wisconsin Water Resources Institute, WIS-WRI-06-01. 